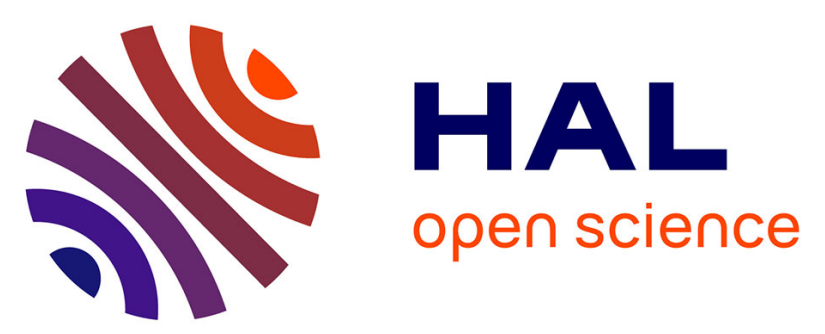

\title{
Eugenol: A Promising Building Block for Synthesis of Radically Polymerizable Monomers
}

Samantha Molina-gutiérrez, Abdelatif Manseri, Vincent Ladmiral, Roberta Bongiovanni, Sylvain Caillol, Patrick Lacroix-desmazes

\section{To cite this version:}

Samantha Molina-gutiérrez, Abdelatif Manseri, Vincent Ladmiral, Roberta Bongiovanni, Sylvain Caillol, et al.. Eugenol: A Promising Building Block for Synthesis of Radically Polymerizable Monomers. Macromolecular Chemistry and Physics, 2019, Bioinspired and Biobased Materials, 220 (14), pp.1900179-1900188. 10.1002/macp.201900179 . hal-02189509

\section{HAL Id: hal-02189509 \\ https://hal.science/hal-02189509}

Submitted on 7 May 2020

HAL is a multi-disciplinary open access archive for the deposit and dissemination of scientific research documents, whether they are published or not. The documents may come from teaching and research institutions in France or abroad, or from public or private research centers.
L'archive ouverte pluridisciplinaire HAL, est destinée au dépôt et à la diffusion de documents scientifiques de niveau recherche, publiés ou non, émanant des établissements d'enseignement et de recherche français ou étrangers, des laboratoires publics ou privés. 


\title{
Eugenol, a promising building block for synthesis of radically polymerizable monomers
}

\author{
Samantha Molina-Gutiérrez, ${ }^{\mathrm{a}, \mathrm{b}}$ Abdelatif Manseri, ${ }^{\mathrm{a}}$ Vincent Ladmiral, ${ }^{\mathrm{a}}$ Roberta Bongiovanni, ${ }^{\mathrm{b}}$ Sylvain \\ Caillol, ${ }^{* a}$ and Patrick Lacroix-Desmazes ${ }^{*^{a}}$ \\ a ICGM, UMR 5253 - CNRS, Université de Montpellier, ENSCM, 240 Avenue Emile \\ Jeanbrau 34296 Montpellier, France \\ ${ }^{\mathrm{b}}$ DISAT, Politecnico di Torino, Torino, Italy
}

\begin{abstract}
*Corresponding authors: Sylvain Caillol, Email: sylvain.caillol@enscm.fr and Patrick
Lacroix-Desmazes, Email: patrick.lacroix-desmazes@enscm.fr
\end{abstract}

\begin{abstract}
Eugenol, a natural phenol currently mainly obtained from clove oil, is an interesting aromatic building block for the synthesis of novel biobased monomers. It could also be obtained from lignin depolymerization, becoming a promising building block due to lignin availability as biomass feedstock. The synthesis of eight monomers derived from eugenol containing polymerizable functional groups was achieved. The (meth)acrylation of eugenol, isoeugenol and dihydroeugenol was performed and the solution homopolymerization of these biobased monomers was studied. Moreover, aiming to prepare functional polymers, the introduction of epoxy and cyclic carbonate groups was executed via modification of the allylic double bond present in eugenol derived methacrylate. Thus, a novel platform of versatile biobased monomers derived from eugenol is presented, opening the opportunity to use them in a wide range of polymerization processes and applications
\end{abstract}

\section{Introduction}

Synthesis of biobased monomers which possess physico-chemical properties that could mimic or even surpass those of their petro-based counterparts or bring additional functionality to polymeric materials has become crucial as a consequence of the current depletion of conventional fossil fuels, the volatility of petroleum prices, environmental concerns and more stringent environmental regulations. Suitable molecules for this purpose can be selected from a vast biomass feedstock that includes terpenes, carbohydrates, lignin derivatives, proteins, vegetable oils and lipids. ${ }^{1,2}$ Recently, several reviews and articles have been published on the synthesis of biobased monomers mostly related to step growth polymerization to yield thermoset polymers such as phenolic, polyepoxides, polyurethanes and a few thermoplastic polymers such as polyesters or polyamides. ${ }^{3-7}$ These molecules contain within their chemical structure several functions such as alcohols, phenols, carboxylic acids and amines allowing direct polycondensation. However, biomass molecules rarely possess suitable reactive functions for radical or ionic chain growth polymerization. Indeed, double bonds in fatty acid are not reactive enough to undergo radical polymerization. ${ }^{8}$ Therefore, the synthesis of biobased monomers containing functional groups with suitable reactivity for chain growth polymerization remains interesting for the development of novel materials and use of different polymerization processes. ${ }^{9,10}$

Different biobased molecules have been modified to introduce into their chemical structure functional groups adapted to radical polymerization such as methacrylates or acrylates. ${ }^{11,12}$ In particular, biobased monomers containing aromatic groups are attractive molecules as they can provide high mechanical and thermal stabilities to materials. Natural phenols can be obtained from cashew nut shell liquid (CNSL), lignin, tannin, palm oil and coconut shell tar. ${ }^{13}$. Molecules 
such as cardanol ${ }^{14,15}$ and vanillin ${ }^{16}$ have already been functionalized to prepare biobased radically polymerizable monomers. Other lignin derivatives such as eugenol could also be envisioned for the development of a new platform of monomers for radical polymerization.

Eugenol is a natural phenol that can be obtained from several plants including clove buds, cinnamon bark, tulsi leaves, turmeric, pepper, ginger, oregano and thyme. ${ }^{17}$ Among its derivatives, isoeugenol, a positional isomer, is one of the main volatiles emitted from petunia (Petunia hybrida) ${ }^{18}$ and it can be also obtained from clove oil ${ }^{19}$ and lignin $^{20}$. Likewise it can be synthesized by isomerization of eugenol. ${ }^{21}$ Eugenol, as a natural phenol, may be a potential alternative to aromatic monomers. Moreover, its allylic double bond allows further reactivity or the production of functional polymers.

Rojo et al. ${ }^{22}$ functionalized eugenol to produce methacrylate derivatives for uses in orthopaedic and dental cements. The methacrylic eugenol derived monomers were synthesized via incorporation of the methacrylic group directly onto the phenol group by reaction with methacryloyl chloride or after introduction of a spacer group to obtain ethoxy eugenyl methacrylate. Both monomers were polymerized in toluene solution. Only low conversion polymers ( $<10 \%$ monomer conversion) were soluble in organic solvent and characterized. It was observed that the reaction proceeded primarily through the methacrylic double bond. Moreover, eugenol methacrylate has also been polymerized under suspension polymerization in aqueous dispersed media conditions using PVA as stabilizer. ${ }^{23}$ In this case, eugenol methacrylate was envisioned as the monomer and the crosslinking agent simultaneously. Microspheres with diameter ranging from 500-800 $\mu \mathrm{m}$ were obtained and their oil absorbency properties were studied.

In the present article, a platform of biobased monomers derived from eugenol is proposed. Eugenol, isoeugenol and dihydroeugenol have been selected as the monomers building blocks (Figure 1). To reduce the risk of hydrolysis of the ester group, methacrylate and acrylate moieties were not introduced directly on the aromatic phenol (Figure 1). Polymerizations of these biobased monomers were carried out through conventional radical polymerization in solution and the different behaviours of these molecules was assessed with regards to the position or absence of allylic or propenyl double bonds.

The preservation of the allyl or propenyl double bonds after the polymerization is desired as this leads to functional polymers. The properties of the resulting polymer materials could then be further tuned via chemical reaction on the residual allyl and propenyl groups to form networks through crosslinking for example.

Alternatively, it is possible to take advantage of the allyl and propenyl double bonds, to convert them into functional groups such as epoxy and cyclic carbonate which could be further reacted with a wide range of reactants such as amines, anhydrides, phenols, or thiols. ${ }^{24,25}$

The syntheses of these monomers result in a novel versatile platform of biobased monomers (Figure 1) with compounds suitable for several kinds of polymerization reactions (e.g. radical, thiol-ene, ringopening reactions,...) and processes (e.g. solution, suspension, emulsion polymerization). This platform could also produce materials with a variety of properties and potential applications. 


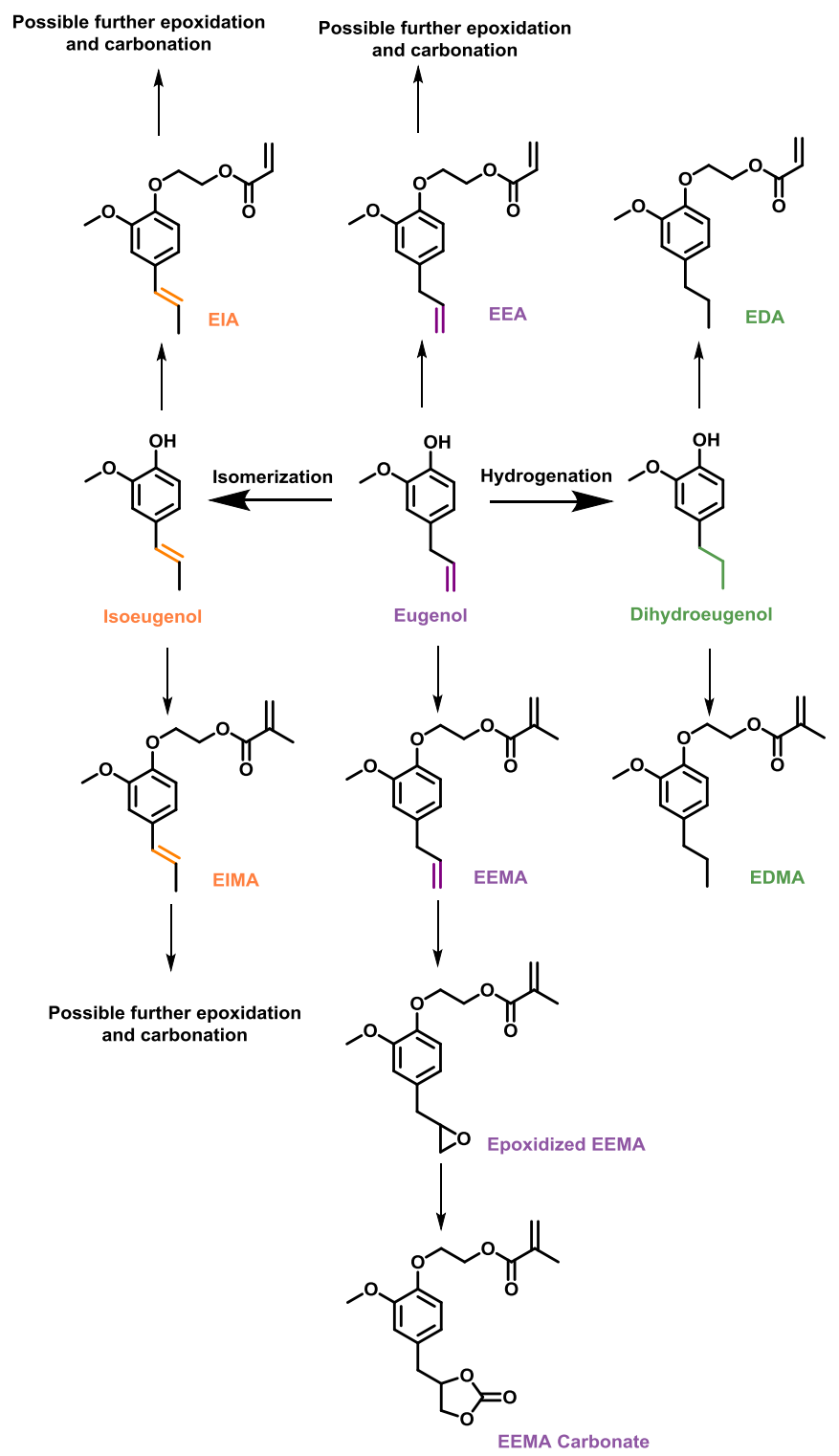

Figure 1. Monomer platform from eugenol derivatives

\section{Experimental}

\section{Materials}

Eugenol (99\%, Aldrich), isoeugenol (99\%, Aldrich, mixture of $8 \%$ cis and $92 \%$ trans), dihydroeugenol (2Methoxy-4-propylphenol, 98\%, Aldrich), ethylene carbonate (98\%, Aldrich), 1,5-diazabicyclo[4.3.0]non5-ene (DBN, 98\%, Aldrich), triethylamine (99.5\%, Aldrich), methacrylic anhydride (94\%, Aldrich), acryloyl choride ( $>97 \%$, Aldrich), m-CPBA ( $<77 \%$, Aldrich), sodium hydrogen carbonate $\left(\mathrm{NaHCO}_{3}\right.$, Aldrich), sodium sulphite $\left(\mathrm{Na}_{2} \mathrm{SO}_{3}, 98 \%\right.$, Aldrich) sodium hydroxide $(\mathrm{NaOH}, 98 \%$, Aldrich), aluminum oxide basic (Aldrich), dichloromethane (DCM, >99\%,VWR), ethyl acetate (>99\%,VWR), sodium sulfate $\left(\mathrm{Na}_{2} \mathrm{SO}_{4},>99 \%\right.$, Aldrich), methanol (MeOH, >99\%, Aldrich), 1,4-bis(trimethylsilyl)benzene (BTMSB, 96\%,Aldrich), tetrabutylammonium bromide ( $>99 \%$, Acros Organics), toluene ( $>99 \%$, Aldrich) were used as received, 2,2'-Azobis(2-methylpropionitrile) (AIBN, Fluka, 98\%) was purified by recrystallization in methanol and dried under vacuum before use. Deionized water (DIW) $\left(1 \mu \mathrm{S} \mathrm{cm}{ }^{-1}\right)$ was obtained using a D8 ion exchange demineralizer from A2E Affinage de L'Eau.

\section{Methods}


General procedure for hydroxyethylation of eugenol and eugenol derivatives. (Figure 2) Eugenol or eugenol derivatives (78.83 g, $480 \mathrm{mmol}, 1$ equiv.) and ethylene carbonate (46.49 g, $528 \mathrm{mmol}, 1.1$ equiv.) were placed in a 2-neck round-bottom flask equipped with a reflux condenser and mixed under argon and high magnetic agitation. The flask was then immersed into an oil bath set to $150{ }^{\circ} \mathrm{C}$. Once the ethylene carbonate had completely melted and the reaction mixture was homogeneous, DBN ( $0.183 \mathrm{~g}$, $1.47 \mathrm{mmol}, 0.003$ equiv.) was injected into the reaction mixture via a syringe. The reaction proceeded at $150{ }^{\circ} \mathrm{C}$ for $30 \mathrm{~min}$, after which the temperature of the oil bath was increased to $180{ }^{\circ} \mathrm{C}$. The reaction was left to proceed for another 4 hours. The product was dissolved in DCM and extracted twice with DI water, to remove any residues of ethylene carbonate. The organic phase was dried with $\mathrm{Na}_{2} \mathrm{SO}_{4}$ and filtered through silica gel to remove any residues of salts.

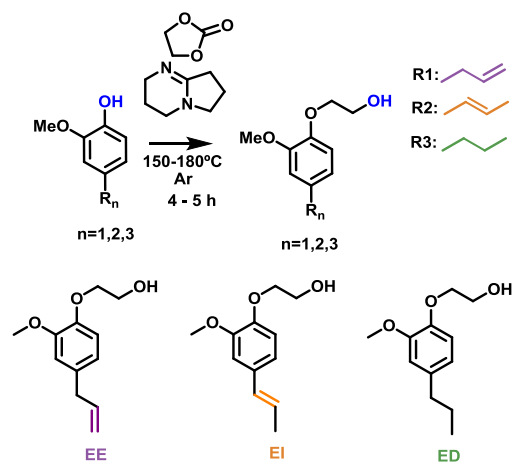

Figure 2. General synthesis of the hydroxyethylated eugenol derivatives

Synthesis of 2-(4-allyl-2-methoxyphenoxy)ethan-1-ol (Ethoxy eugenol) (EE). (ESI Figures S1-S7) Eugenol (78.83 g, $480 \mathrm{mmol}, 1$ equiv.) and ethylene carbonate (46.49 g, $528 \mathrm{mmol}, 1.1$ equiv.), DBN (0.1829 g, $1.47 \mathrm{mmol}, 0.003$ equiv.). Yield: $95 \%$ m.p.: $41^{\circ} \mathrm{C}$.

Synthesis of 2-(2-methoxy-4-(prop-1-en-1-yl)phenoxy)ethan-1-ol (Ethoxy isoeugenol) (EI). (Figures S8S13) Isoeugenol (78.91 g, $8 \%$ cis and $92 \%$ trans, $481 \mathrm{mmol}, 1$ equiv.) and ethylene carbonate $(46.61 \mathrm{~g}$, $529 \mathrm{mmol}, 1.1$ equiv.), DBN (0.1414 g, $1.14 \mathrm{mmol}, 0.002$ equiv.). Yield: $95 \%$. m.p.: $89^{\circ} \mathrm{C}$.

Synthesis of 2-(2-methoxy-4-propylphenoxy)ethan-1-ol (Ethoxy dihydroeugenol) (ED). (Figures S14S20) (79.61 g, $479 \mathrm{mmol}, 1$ equiv.) and ethylene carbonate ( $46.39 \mathrm{~g}, 527 \mathrm{mmol}, 1.1$ equiv.), DBN (0.1629 g, $1.31 \mathrm{mmol}, 0.003$ equiv.). Yield: $97 \%$. m.p.: $53^{\circ} \mathrm{C}$.

General synthesis for eugenol and eugenol derived methacrylates. (Figure 3) Hydroxyethylated eugenol derivative ( 1 equiv.) was placed in a in a round-bottom flask and dissolved in dichloromethane. Triethylamine (2.4 equiv.) was added and the flask sealed with a septum. The mixture was purged with Ar for $15 \mathrm{~min}$ and then immersed in an ice bath. Methacrylic anhydride (1.1 equiv.) was added dropwise over $10 \mathrm{~min}$ to the solution. The reaction proceeded for 18 hours at room temperature. The final mixture was washed three times with $0.05 \mathrm{M} \mathrm{NaOH}$ solution and twice with deionized water, then extracted with ethyl acetate. The organic phase was dried with $\mathrm{Na}_{2} \mathrm{SO}_{4}$, filtered, and the solvent was removed at $30{ }^{\circ} \mathrm{C}$ under vacuum. Finally, the product was purified through flash chromatography using cyclohexane: ethyl acetate 9:1. No radical inhibitor was added. 


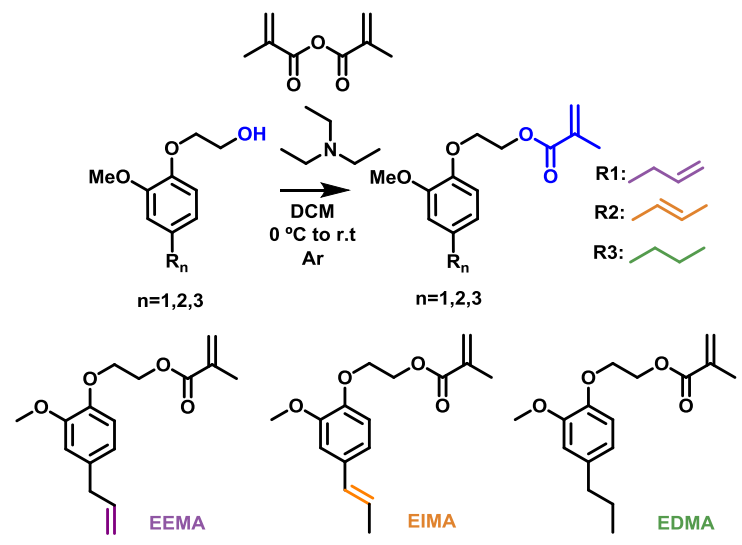

Figure 3. Synthesis of the methacrylated eugenol derivatives

Synthesis of 2-(4-allyl-2-methoxyphenoxy)ethyl methacrylate (Ethoxy eugenyl methacrylate) (EEMA). (Figures S21-S27) EE (93.55 g, $449 \mathrm{mmol}, 1$ equiv.), dichloromethane $(150 \mathrm{~mL})$, triethylamine $(150 \mathrm{~mL}$, $1078 \mathrm{mmol}, 2.4$ equiv.) and methacrylic anhydride (76.67 g, $497 \mathrm{mmol}, 1.1$ equiv.). Yield: 74 \%.

Synthesis of 2-(2-methoxy-4-(prop-1-en-1-yl)phenoxy)ethyl methacrylate (Ethoxy isoeugenyl methacrylate) (EIMA). (Figures S28-S34) EI (75.39 g, 9\% cis and 91\% trans, $362 \mathrm{mmol}, 1$ equiv.), dichloromethane $(150 \mathrm{~mL})$, triethylamine $(120 \mathrm{~mL}, 869 \mathrm{mmol}, 2.4$ equiv.) and methacrylic anhydride (64.18 g, 416 mmol, 1.15 equiv.). Yield: $70 \%$.

Synthesis of 2-(2-methoxy-4-propylphenoxy)ethyl methacrylate (Ethoxy dihydroeugenyl methacrylate) (EDMA). (Figures S35-S40) ED (75.67g, 360 mmol, 1 equiv.), dichloromethane (150 mL), triethylamine $(120 \mathrm{~mL}, 864 \mathrm{mmol}, 2.4$ equiv.) and methacrylic anhydride (62.13 g, 396, 1.12 equiv.). Yield: $88 \%$.

General synthesis for eugenol and eugenol derived acrylates. (Figure 4) Hydroxyethylated eugenol derivative (10.1 g, $48 \mathrm{mmol}, 1$ equiv.) was placed in a round-bottom flask and dissolved in dry dichloromethane $(70 \mathrm{~mL}$ ). Triethylamine $(11 \mathrm{~mL}, 75 \mathrm{mmol}, 1.56$ equiv.) was added and the flask sealed with a septum. The mixture was purged with Ar for $30 \mathrm{~min}$ and then immersed in and ice bath. Acryloyl chloride ( $6 \mathrm{~mL}, 60 \mathrm{mmol}, 1.25$ equiv.) was dissolved in $30 \mathrm{~mL}$ of dichloromethane and added dropwise over $10 \mathrm{~min}$ to the reaction mixture. The reaction proceeded for 1.5 hour at room temperature. The final mixture was filtered and then washed with $0.1 \mathrm{M} \mathrm{NaOH}$ solution twice, with $0.1 \mathrm{M} \mathrm{HCl}$ twice and with deionized water, then the organic phase was dried with $\mathrm{Na}_{2} \mathrm{SO}_{4}$, filtered, and the solvent was removed at $30^{\circ} \mathrm{C}$ under vacuum. Finally, the product was purified through flash chromatography using cyclohexane:ethyl acetate 9:1. No inhibitor was added.

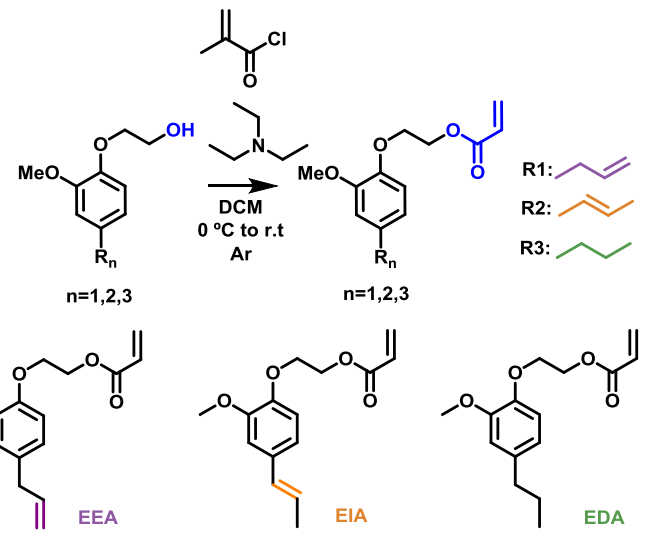


Figure 4. General synthesis of the eugenol derived acrylates

Synthesis of 2-(4-allyl-2-methoxyphenoxy)ethyl acrylate (Ethoxy eugenyl acrylate) (EEA). (Figures S41S44) EE (21.98 g, $105.54 \mathrm{mmol}, 1$ equiv.), triethylamine (23 mL, $165 \mathrm{mmol}, 1.56$ equiv.) and acryloyl chloride (11 mL, $132 \mathrm{mmol}, 1.25$ equiv.). Yield: $68 \%$.

Synthesis of 2-(2-methoxy-4-(prop-1-en-1-yl)phenoxy)ethyl acrylate (Ethoxy isoeugenyl acrylate) (EIA). (Figures S45-S49) El (31.24 g, 9\% cis and 91\% trans, $150 \mathrm{mmol}, 1$ equiv.), triethylamine (33 mL, 234 mmol, 1.56 equiv.) and acryloyl chloride (18 mL, $188 \mathrm{mmol}, 1.25$ equiv.). Yield: $50 \%$.

Synthesis of 2-(2-methoxy-4-propylphenoxy)ethyl acrylate (Ethoxy dihydroeugenyl acrylate) (EDA). (Figures S50-S53) ED (10.1 g, $48 \mathrm{mmol}, 1$ equiv.) dissolved in dry dichloromethane $(70 \mathrm{~mL})$, triethylamine (11 mL, $75 \mathrm{mmol}, 1.56$ equiv.) and acryloyl chloride (6 mL, $60 \mathrm{mmol}, 1.25$ equiv.) dissolved in $30 \mathrm{~mL}$ of DCM. Yield: 81\%.

General procedure for the epoxidation of eugenol derived methacrylates. (Figure 5) Eugenol and isoeugenol derived methacrylates $(10.0109 \mathrm{~g}, 36.19 \mathrm{mmol})$ were dissolved in $60 \mathrm{~mL} \mathrm{DCM}$ and placed in a double necked flask with stirrer and purged with Ar for 15 min. m-CPBA (77\%) (12.16 g (7\%), 54.28 mmol, 1.5 equiv) was dissolved in $180 \mathrm{~mL}$ of DCM and added to the reaction mixture dropwise over 15 min. The reaction was left overnight under $\mathrm{Ar}$ and stirring. Then it was washed first with $250 \mathrm{~mL}$ of $10 \%$ wt of $\mathrm{Na}_{2} \mathrm{SO}_{3}$ aqueous solution, then with $250 \mathrm{~mL}$ of saturated aqueous solution of $\mathrm{NaHCO}_{3}$ and finally with $250 \mathrm{~mL}$ of distilled $\mathrm{H}_{2} \mathrm{O}$. The aqueous phase was extracted with $250 \mathrm{~mL}$ of DCM. The organic phase was dried with $\mathrm{Na}_{2} \mathrm{SO}_{4}$, filtered, and the solvent was removed at $30^{\circ} \mathrm{C}$ under vacuum. Finally, the product was purified through flash chromatography using cyclohexane:ethyl acetate 7:3.

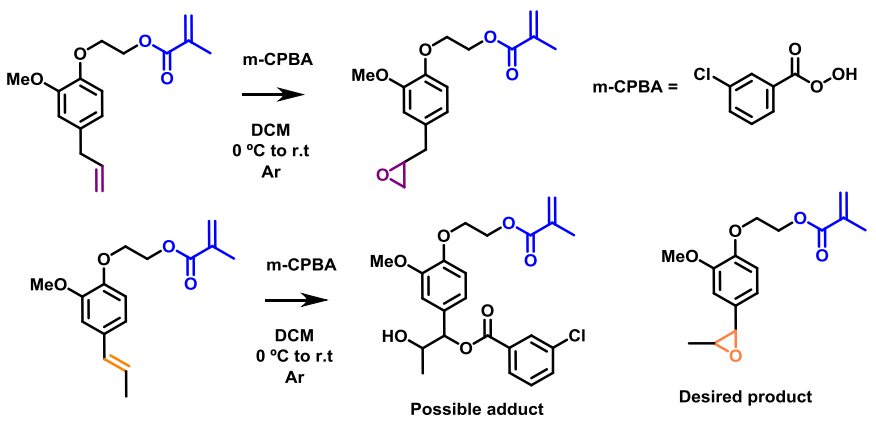

Figure 5. Synthesis of the eugenol derived epoxides

Synthesis of 2-(2-methoxy-4-(oxiran-2-ylmethyl)phenoxy)ethyl methacrylate ( Epoxy Ethoxy eugenyl methacrylate) (Epoxy EEMA). (Figures S54-S57) Eugenol methacrylate, EEMA (10.0109 g, 36.19 mmol), m-CPBA (77\%) (12.16 g (77\%), 54.28 mmol, 1.5 equiv). Yield: $58 \%$.

Synthesis of 2-(2-methoxy-4-((2-oxo-1,3-dioxolan-4-yl)methyl)phenoxy)ethyl methacrylate (Ethoxy eugenyl methacrylate carbonate) (EEMA Carbonate). (Figure 6) (Figures S58-S61) Epoxidized EEMA ( $3.00 \mathrm{~g}, 10.27 \mathrm{mmol}$ ) and tetrabutyl ammonium bromide (0.09g, $0.03 \mathrm{mmol}, 3 \% \mathrm{wt}$ of epoxide) were dissolved in $60 \mathrm{~mL}$ of ethyl acetate. The reaction mixture was placed in a high-pressure stainless steel Parr Reactor equipped with a pressure gage, a turbine impeller and a split ring, which was then filled with $\mathrm{CO}_{2}$ at a pressure of 20 bar. The reactor was heated to $80^{\circ} \mathrm{C}$ and left to react for 48 hours under mechanical stirring. The reactor was depressurized and the reactor mixture was degassed with Ar. Then it was washed three times with $100 \mathrm{~mL} \mathrm{NaHCO}$. The organic phase was dried with $\mathrm{Na}_{2} \mathrm{SO}_{4}$ and the solvent evaporated under vacuum. Yield: $66 \%$. 


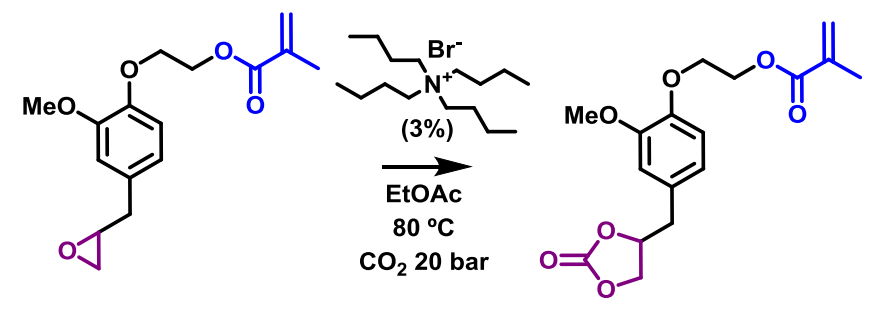

Epoxidized EEMA

EEMA Carbonate

Figure 6. Synthesis of EEMA Carbonate

General procedure for solution homopolymerization of eugenol, isoeugenol and dihydroeugenol derived (meth)acrylates. Eugenol, isoeugenol and dihydroeugenol derived (meth)acrylates (2.763 g, 10 $\mathrm{mmol}), 1,4$-bis(trimethylsilyl)benzene $(0.12 \mathrm{~g}, 0.55 \mathrm{mmol}$ ) and toluene $(6.4 \mathrm{~g})$ were placed in a double necked flask equipped with a condenser. The flask was sealed with a septum and the reaction mixture was purged with argon bubbling for $30 \mathrm{~min}$. The reaction mixture was placed in an oil bath at $70^{\circ} \mathrm{C}$. AIBN ( $0.034 \mathrm{~g}, 1.3 \mathrm{wt} \%$ with respect to the monomer) previously dissolved in toluene $(4 \mathrm{~g})$ and purged with argon for $10 \mathrm{~min}$ was added to the reaction mixture. The monomer conversion was followed by ${ }^{1} \mathrm{H}$ NMR.

\section{Characterization}

Nuclear magnetic resonance spectroscopy (NMR). Chemical structures were determined by ${ }^{1} \mathrm{H}$ NMR and ${ }^{13} \mathrm{C}$ NMR spectroscopies on a Bruker Avance $400 \mathrm{MHz}$ spectrometer at room temperature. The spectra were recorded by dissolving $10 \mathrm{mg}$ or $0.1 \mathrm{~mL}$ of sample in $0.5 \mathrm{~mL}$ of $\mathrm{CDCl}_{3}$. The experimental conditions for recording ${ }^{13} \mathrm{C}$ NMR spectra were as follows: flip angle $30^{\circ}$, acquisition time $2 \mathrm{~s}$, pulse delay $2 \mathrm{~s}$ and 512 scans.

Atmospheric Pressure Solids Analysis Probe (ASAP) time-of-flight mass spectrometry (TOF-MS). ASAP/TOF-MS analyses were performed on a SYNAPT G2-S Mass Spectrometer (Waters) fitted with an Atmospheric Solids Analysis Probe. The samples were deposited directly onto the exterior of a glass capillary and were thermally desorbed. The mass spectra were registered in positive mode from 50 to $1500 \mathrm{Da}$. The corona discharge voltage was $15 \mu \mathrm{A}$ and the sampling cone voltage was $30 \mathrm{~V}$. The temperatures of the source and of desolvation were $140 \circ \mathrm{C}$ and 450 을 respectively. The temperature of thermal desorption was ramped from 50 to $600{ }^{\circ} \mathrm{C}$.

Fourier transform infrared spectroscopy (FTIR). FTIR spectra were acquired on a Thermo Scientific Nicolet 6700 FTIR, and were analyzed using an OMNIC Series 8.2 software from Thermo Scientific.

Size exclusion chromatography (SEC). Polymer molar masses were determined from the THF-soluble fraction by SEC, using a PL-GPC 50 Plus apparatus from Polymer Laboratories (Varian Inc.) equipped with two $300 \mathrm{~mm}$ PL-gel $5 \mu \mathrm{m}$, mixed D (200-400 $\left.000 \mathrm{~g} \mathrm{~mol}^{-1}\right)$ columns thermostated at $35{ }^{\circ} \mathrm{C}$ and a refractive index detector. In addition, a GPC from Agilent Technologies with its corresponding Agilent software, equipped with two PL1113-6300 ResiPore $300 \times 7.5 \mathrm{~mm}$ columns (up to 500,000g/mol) was used. The detector suite comprised a 390-LC PL0390-0601 refractive index detector. The entire SEC$\mathrm{HPLC}$ system was thermostated at $35^{\circ} \mathrm{C}$ Calibration was performed with PMMA narrow standards. THF was used as the eluent at a flow rate of $1 \mathrm{~mL} \mathrm{~min}{ }^{-1}$ and toluene as flow rate marker. Typical sample concentration was $10 \mathrm{mg} / \mathrm{mL}$.

Differential Scanning Calorimetry. Differential Scanning Calorimetry. DSC measurements were performed on 10-15 mg samples on a Netzsch DSC 200 F3 instrument using the following heating/cooling cycle: first cooling ramp from room temperature (ca. $20{ }^{\circ} \mathrm{C}$ ) to -40 at $20{ }^{\circ} \mathrm{C} / \mathrm{min}$, isotherm plateau at $-40{ }^{\circ} \mathrm{C}$ for $10 \mathrm{~min}$, first heating ramp from $-40{ }^{\circ} \mathrm{C}$ to $100{ }^{\circ} \mathrm{C}$ at $20{ }^{\circ} \mathrm{C} / \mathrm{min}$, cooling stage from $100{ }^{\circ} \mathrm{C}$ to $-40{ }^{\circ} \mathrm{C}$ at $10{ }^{\circ} \mathrm{C} / \mathrm{min}$, isotherm plateau at $-40{ }^{\circ} \mathrm{C}$ for $10 \mathrm{~min}$, second heating ramp from $-40{ }^{\circ} \mathrm{C}$ to $100{ }^{\circ} \mathrm{C}$ at $20^{\circ} \mathrm{C} / \mathrm{min}$, cooling ramp to $-40{ }^{\circ} \mathrm{C}$ at $10{ }^{\circ} \mathrm{C} / \mathrm{min}$, isotherm plateau at $-40{ }^{\circ} \mathrm{C}$ for 
$10 \mathrm{~min}$, third heating ramp from $-40{ }^{\circ} \mathrm{C}$ to $100^{\circ} \mathrm{C}$ at $20^{\circ} \mathrm{C} / \mathrm{min}$, and last cooling stage from $100{ }^{\circ} \mathrm{C}$ to room temperature (ca. $20^{\circ} \mathrm{C}$ ). Calibration of the instrument was performed with noble metals and checked with an indium sample.

\section{Results and discussion}

\section{Synthesis of biobased monomers derived from eugenol.}

The successful synthesis of monomers derived from eugenol containing radically polymerizable functional groups such as acrylates and methacrylates was performed. Moreover, the introduction of functional groups such as epoxy and cyclic carbonate to allow further functionalization or crosslinking was also achieved. Thus, the synthesis of six eugenol-derived (meth)acrylate monomers was executed using a two-step synthesis procedure. ${ }^{15}$ The first step was a chain elongation whereby an ethyl spacer was introduced, to move the hydroxyl group away from the aromatic ring. This was done to increase the stability of the ester group of the methacrylate function (to avoid possible hydrolysis). This reaction was performed without solvent, at high temperature $\left(150-180^{\circ} \mathrm{C}\right)$ for $4-5$ hours using DBN as catalyst. Reactions went to full conversion and yields were quantitative for all the eugenol derivatives. In the case of the eugenol, after the introduction of the spacer group, $3 \% \mathrm{~mol}$ of isoeugenol derivative was observed (Figures S6). This isomerisation was probably caused by the high temperature and the presence of DBN. The second step was the introduction of the (meth)acrylate group using methacrylic anhydride or acryloyl chloride respectively, in the presence of triethylamine. The reactions were carried out between $0^{\circ} \mathrm{C}$ and room temperature and lasted 15-20 hours in the case of methacrylation and 2 hours in the case of acrylation. The methacrylate monomers were produced with quantitative conversion and then purified by a flash chromatography method using cyclohexane and ethyl acetate binary mixture as eluent. Although the reactions were executed using DCM as a solvent, they can also be carried out in ethyl acetate as a non-toxic solvent. NMR spectroscopy confirmed the preparation of the desired products synthesized in ethyl acetate (Figures S62-S63).

After the successful synthesis of the (meth)acrylated monomers, the introduction of functional groups such as epoxy and cyclic carbonate was explored as this could allow the synthesis of other types of functional biobased polymers.

The epoxidation of the methacrylated monomers was carried out in DCM using $\mathrm{m}-\mathrm{CPBA}$ as oxidant. This method was successful in the case of EEMA. However, in the case of EIMA, a secondary product was formed by opening of the epoxy ring by chloro-benzoic acid. Thus, another way reported in literature to do the epoxidation is by using Oxone ${ }^{\circledR}$ in acetone, ${ }^{26}$ which could help not only to avoid the ring opening but also as a greener synthetic reaction. Epoxidation of internal double bonds has been done successfully with this method. ${ }^{26}$ Thus, this reaction was executed with EIMA and the desired epoxide was obtained with conversion of $76 \%$ (Figure S64). Therefore, the carbonate derivative from EIMA should not be discarded in the pursuit of a broader monomer platform.

The carbonation of the eugenol methacrylate EEMA was successfully achieved. Tetrabutyl ammonium bromide was used to catalyse the reaction which was carried out under a $\mathrm{CO}_{2}$ pressure of 20 bar. $^{27-30}$ This carbonate derivative could be used for further reaction, for example as a crosslinker through addition reactions with amines. ${ }^{31-33}$

\section{Solution polymerization of eugenol derived (meth)acrylates.}

After the synthesis of the novel platform of biobased monomers derived from eugenol, it was important to study the behaviour of these monomers in radical homopolymerization. The solution polymerization of the eugenol derived monomers was performed in toluene $(21 \%$ solids $)$ at $70^{\circ} \mathrm{C}$, with AIBN as initiator (1.3 wt\% with respect to the monomer) and the monomer conversion was monitored by ${ }^{1} \mathrm{H}-\mathrm{NMR}$. The monomer conversion was determined each hour for the first 7 hours of reaction and then measured after 24 hours reaction (Figure 7). No additional initiator was added during the course of the reaction. 
The homopolymerization of EDMA (monomer without any other unsaturation than the methacrylate) reached quantitative monomer conversion (97\%) after $24 \mathrm{~h}$.

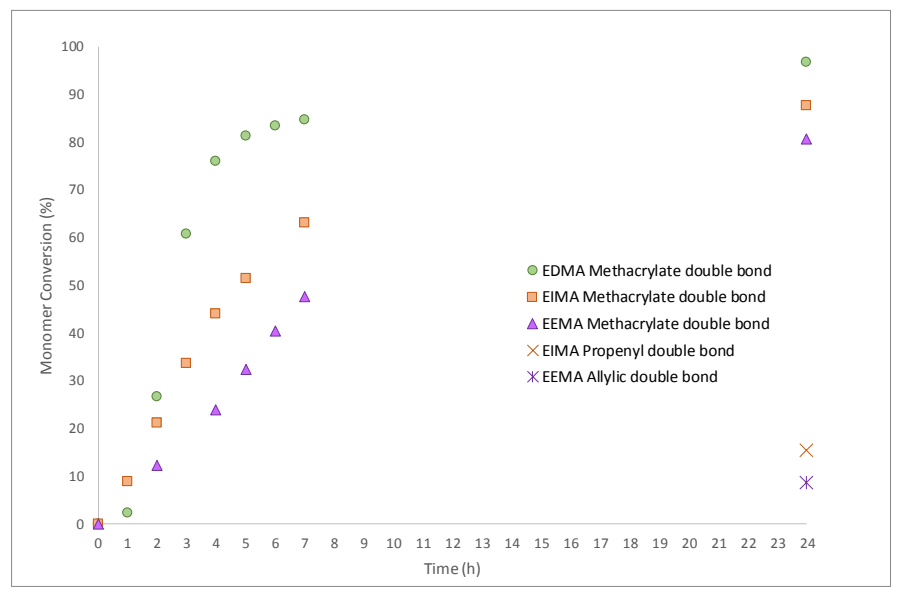

Figure 7. Monomer conversion of eugenol derived methacrylates in toluene solution homopolymerization at $70^{\circ} \mathrm{C}$.

Although EIMA and EEMA also reached high conversion after $24 \mathrm{~h}$ ( $80 \%$ conversion), the reaction rate $R_{p}$ was noticeably slower throughout the entire reaction: $R_{p, E D M A} \gg R_{p, E I M A}>R_{p, E E M A}$ (Figure S67). The presence of allylic or propenyl moieties (in the eugenol and isoeugenol derived methacrylates, respectively), can induce secondary reactions during polymerization. Degradative chain transfer reactions such as allylic proton abstraction may occur and lead to a decrease of the polymerization rate. $^{34-36}$

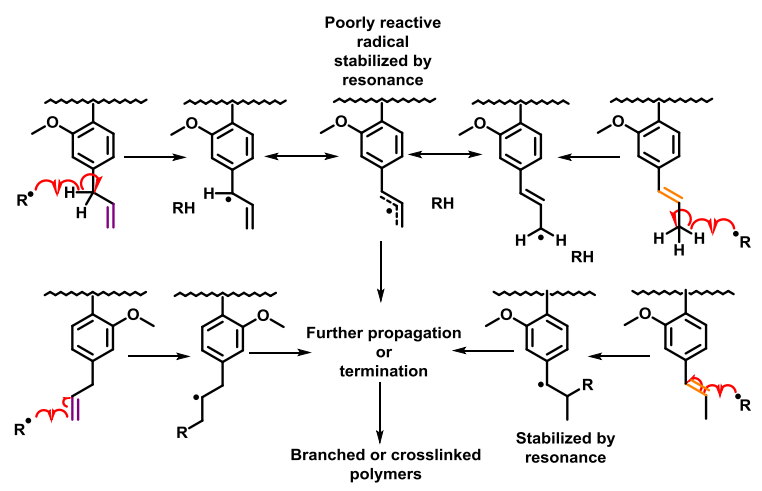

Figure 8. Chain transfer and radical addition

The abstraction of a hydrogen atom from both allyl and propenyl derivatives will indeed lead to virtually the same allylic radical strongly stabilized by resonance (Figure 8). Moreover, radical addition can also occur directly on the double bond. Both reactions can lead to propagation (although with low probability considering the poorly reactive resonance-stabilized radical) or more probably to termination with either a radical derived from the initiator (primary termination) or with a growing polymer radical. These $\mathrm{H}$-abstraction reactions leading to resonance-stabilized radicals less prone to propagation, would ultimately result in lower polymerization rates (termination) and in branched and eventually crosslinked polymers. The consumption of the double bond was also studied by ${ }^{1} \mathrm{H}$ NMR spectroscopy. It was observed that in the case of EEMA after 24 hours of reaction, $9 \%$ of the allylic 
double bonds and $81 \%$ of the methacrylate double bonds were consumed. In case of EIMA, $15 \%$ of the propenyl double bonds and $88 \%$ of the methacrylate double bonds were consumed after 24 hours (Figure 7). This gives a ratio of 9:1 methacrylate double bonds/allylic double bonds consumption for EEMA and 5.8:1 methacrylate double bonds/propenyl double bonds consumption for EIMA.

Table 1. Characterization of homopolymers from eugenol derived acrylates and methacrylates

\begin{tabular}{|c|c|c|c|c|c|c|c|c|}
\hline Monomer & $\begin{array}{c}\text { Monomer } \\
\text { conversion \% } \\
\text { (7h) }\end{array}$ & $\begin{array}{c}\text { Monomer } \\
\text { conversion } \\
\% \\
\text { (24h) }\end{array}$ & $\begin{array}{c}\mathrm{T}_{\mathrm{g}} \\
\left({ }^{\circ} \mathrm{C}\right)\end{array}$ & $\begin{array}{c}\text { Gel } \\
\text { formation }\end{array}$ & $\begin{array}{c}\mathrm{M}_{\mathrm{n}} \\
\left(\mathrm{g} \mathrm{mol}^{-1}\right) \\
(7 \mathrm{~h})\end{array}$ & $\begin{array}{c}\oplus \\
(7 \mathrm{~h})\end{array}$ & $\begin{array}{c}\mathrm{M}_{\mathrm{n}} \\
\left(\mathrm{g} \mathrm{mol}^{-1}\right) \\
(24 \mathrm{~h})\end{array}$ & $\begin{array}{c}\oplus \\
(24 \mathrm{~h})\end{array}$ \\
\hline EDMA & 85 & 97 & 21 & No & 26,900 & 2.3 & 26,700 & 2.5 \\
\hline EIMA & 63 & 88 & 40 & No & 21,400 & 3.0 & 28,900 & 3.3 \\
\hline EEMA & 48 & 81 & 31 & No & 19,700 & 2.3 & 28,000 & Multimodal \\
\hline EDA & $91(6 \mathrm{~h})$ & 94 & 10 & No & 16,300 & 3.0 & 14,000 & 3.5 \\
\hline EIA & 25 & ND & ND & Yes & 17,500 & 3.8 & ND & ND \\
\hline EEA & 36 & 61 & 27 & No & 9,500 & 3.0 & 15,900 & Multimodal \\
\hline
\end{tabular}

Thus, the propenyl double bond proved to be slightly more reactive than the allylic double bond. However, the mechanism followed by the allylic and propenyl double bonds seems to differ. Previous studies indicate that the propenyl groups are more prone to cross-propagation than to $\mathrm{H}$-abstraction. ${ }^{37}$ It was also possible to monitor the consumption of the allylic protons $-\mathrm{Ar}-\mathrm{CH}_{\mathbf{2}}-\mathrm{CH}=\mathrm{CH}_{2}$ in the case of EEMA. It was found that $10 \%$ of the allylic protons had been consumed after $24 \mathrm{~h}$. This means that there is a small abstraction of the allylic protons (10\%) with the preservation of $91 \%$ of the allylic double bond occurring. Even though secondary reactions were present, the final polymers remained soluble in toluene. The monomers conversions were calculated both with the signals of the polymer (using the unreactive methoxy group as a reference) and by using the signal of an internal standard (1,4bis(trimethylsilyl)benzene, BTMSB) (ESI Figures S65-S66). The results obtained by both methods were equal, thus confirming the absence of an insoluble fraction. SEC measurements after 7 hours of reaction (Table 1) show that the molar masses of poly(EEMA) and poly(EIMA) were lower than that of poly(EDMA). This is consistent with the occurrence of chain transfer during the polymerization of EEMA and EIMA. Furthermore, at longer reaction time (24 hours), the average molar masses of poly(EEMA) and poly(EIMA) increased and the dispersity increased steadily for poly(EEMA) (multimodal) (Table 1) (Figures S69-S70). This suggests the formation of branched polymers. It is important to mention that the preservation of residual allylic and propenylic double bonds in the polymers was desired as it gives the opportunity to execute further crosslinking reactions or post-functionalisation of the polymers.

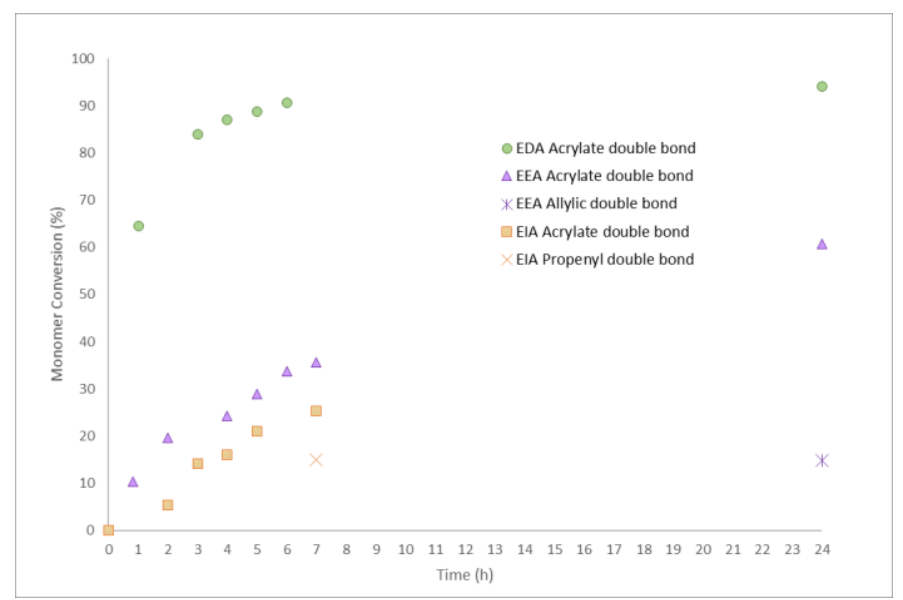

Figure 9. Monomer conversion of eugenol derived acrylates in solution homopolymerization 
The eugenol derived acrylates behaved slightly differently (Figure S68). The solution homopolymerization of EDA reached high conversion in 6 hours (Table 1 and Figure 9), as expected (higher reactivity of the acrylate derivative compared to the analogous methacrylate in radical polymerization). ${ }^{38,39}$ The molar mass of the poly(EDA) is lower at $24 \mathrm{~h}$ than at $7 \mathrm{~h}$. This behaviour is consistent with the kinetics of conventional radical polymerization (quasi-steady-state approximation), where the initiation rate is approximated to be constant. Thus, as the concentration of monomer decreases during the polymerization, the kinetic chain length diminishes with the increase of monomer conversion (Eq.1) resulting in the lowering of average molecular weight with time.

$$
v=\frac{k_{p}[M]}{2\left(f k_{d} k_{t}[I]\right)^{1 / 2}} \quad E q .1
$$

Where $k_{\mathrm{p}}, \mathrm{k}_{\mathrm{d}}$ and $\mathrm{k}_{\mathrm{t}}$ are the rate constants of propagation, decomposition and termination respectively, $f$ is the initiator efficiency and $[\mathrm{M}]$ and $[\mathrm{I}]$ are the monomer and initiator concentration.

In the case of the EEA and EIA, a lower conversion was reached in comparison with their methacrylate counterparts. Furthermore, after 24 hours, the polymerization of EIA led to the formation of a gel insoluble in toluene.

The monomer conversion was monitored by ${ }^{1} \mathrm{H}$ NMR through direct integration of the polymer and monomer signals (using the unreactive methoxy group as a reference) and also against the signal of the internal standard (BTMSB). In the case of the EDA and EEA polymerizations, monomer conversions were identical irrespective of the use of internal standard, implying that there was no gel formation during the polymerization. In contrast, for EIA polymerization, the two methods used to calculate conversion led to slightly different values. This suggests that gel formation occurred during the first hours of the reaction, producing a crosslinked insoluble material. The consumption of the allylic and propenyl double bonds was monitored by ${ }^{1} \mathrm{H}-\mathrm{NMR}$. In the case of EEA, $8 \%$ of the allylic double bonds and $36 \%$ of the acrylate double bonds were consumed after 7 hours of polymerization, whereas for EIA (soluble fraction), $12 \%$ of the propenyl double bonds and $25 \%$ of the acrylate double bonds were consumed during the same period of time (Figure 9). This gives a ratio of 4.5:1 acrylate double bonds: allylic double bonds consumption for EEA and 2.1:1 acrylate double bonds: propenyl double bonds consumption for EIA. This last value for EIA being related to only the soluble fraction of the reaction media, the overall consumption of propenyl double bonds is underestimated and thought to be higher than $12 \%$. Thus, in this polymerization, propenyl double bonds conversion might be due to a close reactivity compared to the acrylate function towards propagation, leading to fast gelation (cross-propagation). However, it might also be due to the higher reactivity of poly(alkyl acrylate) radical towards $\mathrm{H}$-abstraction, compared to poly(alkyl methacrylate) radical. The combination of a lower reactivity of the allylic double bonds compared to the propenyl double bonds (i.e. smaller extent of cross-propagation with acrylate) and the higher propensity to degradative chain transfer of the allylic protons (reflected by the lower molar masses, Table 1 at 7 hours) delays gelation in the case of EEA compared to EIA. Nevertheless, the increase of dispersity with EEA conversion, from 3.0 at $36 \%$ conversion up to 8.7 (multimodal) at $61 \%$ conversion (Table 1), and the increase of molar masses clearly visible in the SEC chromatogram (Figures S71-S72) are signs of significant chain branching. Moreover, the consumption of the allylic protons was calculated and it was found that $15 \%$ of them had been consumed in the homopolymerization after 24 hours. Similarly, in the case of EIA the monitoring of the propenyl protons showed a consumption of above $16 \%$ after 7 hours (underestimated due to formation of insoluble fraction), which is slightly higher than the propenyl double bonds consumption of $12 \%$. Nevertheless, approximately $83 \%$ of the allylic double bonds of EEA remained unreacted after 24 hours of reaction, and available for crosslinking or post functionalisation of the polymers.

There was a decrease of the $\mathrm{T}_{\mathrm{g}}$ of about $10^{\circ} \mathrm{C}$ between poly(methacrylates) and poly(acrylates) (Table 1, Figures S73-S77). At first sight, this small difference is quite surprising, but small differences of $T_{g}$ between poly(acrylates) and poly(methacrylates) have already been observed in polymers such as poly(isobornyl methacrylate) $\left(T_{g}=110^{\circ} \mathrm{C}\right)$ and poly(isobornyl acrylate) $\left(T_{g}=94^{\circ} \mathrm{C}\right) .{ }^{40}$ Moreover, the 
secondary reactions involving the pending propenyl and allylic moieties may also contribute to this uncommon difference in $\mathrm{T}_{\mathrm{g}}$ between these biobased poly(methacrylates) and poly(acrylates).

Homopolymerization of epoxy and carbonate derivatives was not in the scope of the present work as these derivatives are intended to be used as additives in copolymer formulations for further crosslinking reactions.

\section{Conclusions}

The syntheses of seven novel biobased eugenol derived monomers are presented: ethoxy isoeugenyl methacrylate (EIMA), ethoxy dihydroeugenyl methacrylate (EDMA), ethoxy eugenyl acrylate (EEA), ethoxy isoeugenyl acrylate (EIA), ethoxy dihydroeugenyl acrylate (EDA), epoxy EEMA and EEMA carbonate. The monomers were homopolymerized in solution ( $21 \%$ solids content) in toluene. These polymers exhibited $\mathrm{T}_{\mathrm{g}}$ between $10^{\circ} \mathrm{C}$ and $40^{\circ} \mathrm{C}$. High monomer conversions were obtained in the case of methacrylates: EDMA (98\%), EIMA (89\%) and EEMA (84\%). The lower polymerization rates observed in the case of EIMA and EEMA compared to EDMA were probably a result of degradative chain transfer reactions (hydrogen abstraction of allylic protons) and cross-propagation (on the propenyl double bonds), both leading to resonance-stabilized poorly reactive radicals. Nevertheless, residual allylic and propenyl double bonds remained in the poly(EEMA) and poly(EIMA) polymers which are thus functional. The remaining allylic and propenyl double bonds can be used to carry out further reactions such as crosslinking or post-functionalizations. For acrylates, the polymerization reached high conversion for EDA (94\%), but a lower conversion was obtained for EEA (61\%) and gelation was observed in the case of EIA (insoluble poly(EIA) homopolymer). In homopolymerization of the biobased methacrylate and acrylate monomers, considering both the decrease of the polymerization rate and the production of branched polymers, the extent of the secondary reactions taking place on the allylic and propenyl moieties follows the decreasing order order: EIA >>EEA >EEMA>EIMA. Nevertheless, in copolymerization with acrylates, EIMA is expected to show more side reactions than EEMA due to the higher reactivity of acrylates towards propenyl double bond. The resulting functional polymers possessing pending allylic or propenyl double bonds can be further functionalized to tune their properties and applications. Eugenolderived monomers containing an epoxy or carbonate functional group can be used in different concentrations in copolymers formulations as additives to tune the properties of the polymers by nonradical crosslinking reactions.

\section{Conflicts of interest}

There are no conflicts to declare.

\section{Acknowledgements}

This work was funded through a SINCHEM Grant. SINCHEM is a Joint Doctorate programme selected under the Erasmus Mundus Action 1 Programme (FPA 2013-0037). The authors also thank Synthomer (UK) Ltd for financial support of their research on biobased polymers as well as for fruitful discussions (Dr. Peter Shaw and Dr. Renaud Perrin). The ASAP HR-MS analyses were performed by the 'Laboratoire de Mesures Physiques', analytical facilities of Montpellier. Samantha Molina-Gutiérrez thanks Céline Bonneaud, Yvan Echochard and Andrea Ruiu for their kind assistance during this work. 


\section{Table of Contents Entry}

A novel platform of versatile biobased monomers derived from eugenol is presented and their radical polymerization is studied.

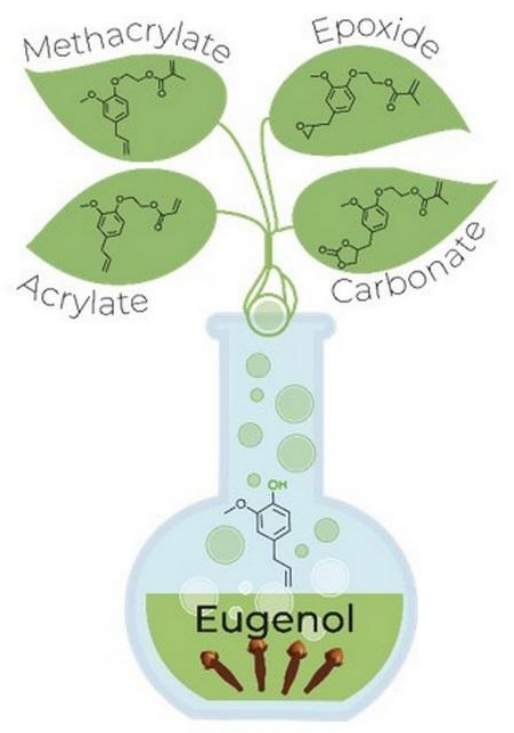

\section{References}

(1) Corma, A.; Iborra, S.; Velty, A. Chemical Routes for the Transformation of Biomass into Chemicals. Chem. Rev. 2007, 107 (6), 2411-2502. https://doi.org/10.1021/cr050989d.

(2) Sheldon, R. A. Green and Sustainable Manufacture of Chemicals from Biomass: State of the Art. Green Chem. 2014, 16 (3), 950-963. https://doi.org/10.1039/c3gc41935e.

(3) Gallezot, P. Conversion of Biomass to Selected Chemical Products. Chem. Soc. Rev. 2012, 41 (4), 1538-1558. https://doi.org/10.1039/C1CS15147A.

(4) Ca, V.; Lligadas, G.; Ronda, J. C.; Galia, M.; Galià, M.; Cádiz, V. Renewable Polymeric Materials from Vegetable Oils: A Perspective. Mater. Today 2013, 16 (9), 337-343. https://doi.org/10.1016/j.mattod.2013.08.016.

(5) Harmsen, P. F. H.; Hackmann, M. M.; Bos, H. L. Green Building Blocks for Bio-Based Plastics. Biofuels, Bioprod. Biorefining 2014, 8 (3), 306-324. https://doi.org/10.1002/bbb.1468.

(6) Gandini, A.; Lacerda, T. M. From Monomers to Polymers from Renewable Resources: Recent Advances. Prog. Polym. Sci. 2015, 48, 1-39.

https://doi.org/10.1016/j.progpolymsci.2014.11.002.

(7) Gandini, A.; Lacerda, T. M.; Carvalho, A. J. F. F.; Trovatti, E. Progress of Polymers from Renewable Resources: Furans, Vegetable Oils, and Polysaccharides. Chem. Rev. 2016, 116 (3), 1637-1669. https://doi.org/10.1021/acs.chemrev.5b00264.

(8) Petrovic, Z. Polyurethanes from Vegetable Oils. Polym. Rev. 2008, 48 (1), 109-155. https://doi.org/10.1080/15583720701834224.

(9) Molina-Gutiérrez, S.; Ladmiral, V.; Bongiovanni, R.; Caillol, S.; Lacroix-Desmazes, P. Radical Polymerization of Biobased Monomers in Aqueous Dispersed Media. Green Chem. 2019, 21 (1), 36-53. https://doi.org/10.1039/C8GC02277A.

(10) Li, W. S. J.; Ladmiral, V.; Takeshima, H.; Satoh, K.; Kamigaito, M.; Semsarilar, M.; Negrell, C.; Lacroix-Desmazes, P.; Caillol, S. Ferulic Acid-Based Reactive Core-Shell Latex by Seeded Emulsion 
Polymerization. Polym. Chem. 2019. https://doi.org/10.1039/C9PY00079H.

(11) Kristufek, S. L.; Wacker, K. T.; Tsao, Y.-Y. T. Y. T.; Su, L.; Wooley, K. L. Monomer Design Strategies to Create Natural Product-Based Polymer Materials. Nat. Prod. Rep. 2017, 34 (4), 433-459. https://doi.org/10.1039/c6np00112b.

(12) Lomège, J.; Lapinte, V.; Negrell, C.; Robin, J.-J.; Caillol, S. Fatty Acid-Based Radically Polymerizable Monomers: From Novel Poly(Meth)Acrylates to Cutting-Edge Properties. Biomacromolecules 2019, 20 (1), 4-26. https://doi.org/10.1021/acs.biomac.8b01156.

(13) Lochab, B.; Shukla, S.; Varma, I. K. Naturally Occurring Phenolic Sources: Monomers and Polymers. RSC Adv. 2014, 4 (42), 21712-21752. https://doi.org/10.1039/c4ra00181h.

(14) Ladmiral, V.; Jeannin, R.; Fernandes Lizarazu, K.; Lai-Kee-Him, J.; Bron, P.; Lacroix-Desmazes, P.; Caillol, S. Aromatic Biobased Polymer Latex from Cardanol. Eur. Polym. J. 2017, 93, 785-794. https://doi.org/10.1016/j.eurpolymj.2017.04.003.

(15) Li, W. S. J.; Negrell, C.; Ladmiral, V.; Lai-Kee-Him, J.; Bron, P.; Lacroix-Desmazes, P.; JolyDuhamel, C.; Caillol, S. Cardanol-Based Polymer Latex by Radical Aqueous Miniemulsion Polymerization. Polym. Chem. 2018, 9 (18), 2468-2477. https://doi.org/10.1039/C8PY00167G.

(16) Fache, M.; Darroman, E.; Besse, V.; Auvergne, R.; Caillol, S.; Boutevin, B. Vanillin, a Promising Biobased Building-Block for Monomer Synthesis. Green Chem. 2014, 16 (4), 1987-1998. https://doi.org/10.1039/C3GC42613K.

(17) Khalil, A. A.; Rahman, U. ur; Khan, M. R.; Sahar, A.; Mehmood, T.; Khan, M. Essential Oil Eugenol: Sources, Extraction Techniques and Nutraceutical Perspectives. RSC Adv. 2017, 7 (52), 3266932681. https://doi.org/10.1039/C7RA04803C.

(18) Verdonk, J. C.; De Vos, C. H. R.; Verhoeven, H. A.; Haring, M. A.; Van Tunen, A. J.; Schuurink, R. C. Regulation of Floral Scent Production in Petunia Revealed by Targeted Metabolomics. Phytochemistry 2003, 62 (6), 997-1008. https://doi.org/10.1016/S0031-9422(02)00707-0.

(19) Zhao, L.; Xie, Y.; Chen, L.; Xu, X.; Zhao, C. X.; Cheng, F. Efficient Biotransformation of Isoeugenol to Vanillin in Recombinant Strains of Escherichia Coli by Using Engineered Isoeugenol Monooxygenase and Sol-Gel Chitosan Membrane. Process Biochem. 2018, 71 (December 2017), 76-81. https://doi.org/10.1016/j.procbio.2018.05.013.

(20) Wang, L.; Zhang, R.; Li, J.; Guo, L.; Yang, H.; Ma, F.; Yu, H. Comparative Study of the Fast Pyrolysis Behavior of Ginkgo, Poplar, and Wheat Straw Lignin at Different Temperatures. Ind. Crops Prod. 2018, 122 (May), 465-472. https://doi.org/10.1016/j.indcrop.2018.06.038.

(21) Alupei, V.; Ritter, H. Mikrowellensynthesen Unter Normaldruck. Nachrichten aus der Chemie 2005, 53 (5), 518-522. https://doi.org/10.1002/nadc.20050530508.

(22) Rojo, L.; Vazquez, B.; Parra, J.; López Bravo, A.; Deb, S.; San Roman, J. From Natural Products to Polymeric Derivatives of "Eugenol": A New Approach for Preparation of Dental Composites and Orthopedic Bone Cements. Biomacromolecules 2006, 7 (10), 2751-2761. https://doi.org/10.1021/bm0603241.

(23) Deng, J.; Yang, B.; Chen, C.; Liang, J. Renewable Eugenol-Based Polymeric Oil-Absorbent Microspheres: Preparation and Oil Absorption Ability. ACS Sustain. Chem. Eng. 2015, 3 (4), 599605. https://doi.org/10.1021/sc500724e.

(24) Vidil, T.; Tournilhac, F.; Musso, S.; Robisson, A.; Leibler, L. Control of Reactions and Network Structures of Epoxy Thermosets. Prog. Polym. Sci. 2016, 62, 126-179.

https://doi.org/10.1016/j.progpolymsci.2016.06.003.

(25) Yadav, N.; Seidi, F.; Crespy, D.; D'Elia, V. Polymers Based on Cyclic Carbonates as Trait d'Union Between Polymer Chemistry and Sustainable CO 2 Utilization. ChemSusChem 2019, 12 (4), 724754. https://doi.org/10.1002/cssc.201802770.

(26) Ferraz, H. M. C.; Muzzi, R. M.; De O. Vieira, T.; Viertler, H. A Simple and Efficient Protocol for Epoxidation of Olefins Using Dimethyldioxirane. Tetrahedron Lett. 2000, 41 (26), 5021-5023. 
https://doi.org/10.1016/S0040-4039(00)00769-3.

(27) Yamaguchi, K.; Ebitani, K.; Yoshida, T.; Yoshida, H.; Kaneda, K. Mg-Al Mixed Oxides as Highly Active Acid-Base Catalysts for Cycloaddition of Carbon Dioxide to Epoxides. J. Am. Chem. Soc. 1999, 121 (18), 4526-4527. https://doi.org/10.1021/ja9902165.

(28) Tamami, B.; Sohn, S.; Wilkes, G. L. Incorporation of Carbon Dioxide into Soybean Oil and Subsequent Preparation and Studies of Nonisocyanate Polyurethane Networks. J. Appl. Polym. Sci. 2004, 92 (2), 883-891. https://doi.org/10.1002/app.20049.

(29) Doll, K. M.; Erhan, S. Z. The Improved Synthesis of Carbonated Soybean Oil Using Supercritical Carbon Dioxide at a Reduced Reaction Time. Green Chem. 2005, 7 (12), 849. https://doi.org/10.1039/b511014a.

(30) Doll, K. M.; Erhan, S. Z. Synthesis of Carbonated Fatty Methyl Esters Using Supercritical Carbon Dioxide. J. Agric. Food Chem. 2005, 53 (24), 9608-9614. https://doi.org/10.1021/jf0516179.

(31) Webster, D. C.; Crain, A. L. Synthesis and Applications of Cyclic Carbonate Functional Polymers in Thermosetting Coatings. Progress in Organic Coatings. 2000, pp 275-282. https://doi.org/10.1016/S0300-9440(00)00114-4.

(32) Suzuki, A.; Nagai, D.; Ochiai, B.; Endo, T. Facile Synthesis and Crosslinking Reaction of Trifunctional Five-Membered Cyclic Carbonate and Dithiocarbonate. Journal of Polymer Science, Part A: Polymer Chemistry. 2004, pp 5983-5989. https://doi.org/10.1002/pola.20436.

(33) Camara, F.; Caillol, S.; Boutevin, B. Free Radical Polymerization Study of Glycerin Carbonate Methacrylate for the Synthesis of Cyclic Carbonate Functionalized Polymers. Eur. Polym. J. 2014, 61, 133-144. https://doi.org/10.1016/j.eurpolymj.2014.10.001.

(34) Gaylord, N. G. Allyl Polymerization. IV. Effective Chain Transfer in Polymerization of Allylic Monomers. J. Polym. Sci. 1956, 22 (100), 71-78. https://doi.org/10.1002/pol.1956.1202210010.

(35) Aota, H.; Matsumoto, A.; Kumagai, T.; Kawasaki, H.; Arakawa, R.; Aota, H.; Kawasaki, H.; Arakawa, R. Reassessment of Free-Radical Polymerization Mechanism of Allyl Acetate Based on End-Group Determination of Resulting Oligomers by MALDI-TOF-MS Spectrometry. Polym. J. 2009, 41 (1), 26-33. https://doi.org/10.1295/polymj.pj2008174.

(36) Zhang, Y.; Dubé, M. A.; Vivaldo-Lima, E. Modeling Degradative Chain Transfer in d -Limonene/ n Butyl Methacrylate Free-Radical Copolymerization. J. Renew. Mater. 2015, 3 (4), 318-326. https://doi.org/10.7569/JRM.2015.634115.

(37) Barson, C. A.; Bevingtont, J. C.; Hunt, B. J. The Effects of Some Phenyl Derivatives of Propene upon Radical Polymerizations. 1998, 39 (97), 1345-1350.

(38) Van Herk, A. M. Pulsed Initiation Polymerization as a Means of Obtaining Propagation Rate Coefficients in Free-Radical Polymerizations. II Review up to 2000. Macromol. Theory Simulations 2000, 9 (8), 433-441. https://doi.org/10.1002/1521-3919(20001101)9:8<433::AIDMATS433>3.0.CO;2-I.

(39) Beuermann, S.; Buback, M. Rate Coefficients of Free-Radical Polymerization Deduced from Pulsed Laser Experiments. Prog. Polym. Sci. 2002, 27 (2), 191-254. https://doi.org/10.1016/S0079-6700(01)00049-1.

(40) Sigma-Aldrich. Thermal Transitions of Homopolymers: Glass Transition \& Melting Point https://www.sigmaaldrich.com/technical-documents/articles/materials-science/polymerscience/thermal-transitions-of-homopolymers.html (accessed Apr 8, 2019). 